\title{
The Effect of Ectopic Fat on Graft Function After Living Kidney Transplantation
}

\author{
F. THIEME ${ }^{1}$, L. JANOUSEK ${ }^{1}$, J. FRONEK ${ }^{1}$, A. KRALOVA ${ }^{2}$, S. CEJKOVA ${ }^{2}$, \\ I. KRALOVA LESNA ${ }^{2}$, R. POLEDNE ${ }^{2}$
}

${ }^{1}$ Transplant Surgery Department, Institute for Clinical and Experimental Medicine, Prague, Czech Republic, ${ }^{2}$ Laboratory for Atherosclerosis Research, Centre of Experimental Medicine, Institute for Clinical and Experimental Medicine, Prague, Czech Republic

Received September 3, 2015

Accepted September 21, 2015

\section{Summary}

Renal transplantation is associated with a large number of risk factors that can have an influence on early renal graft function (ERGF). One of these factors could be the increasing number of obese kidney donors. The mechanisms of reduced ERGF in obese kidney donors are still poorly understood. To that end, we compared ERGF in recipients with body mass index (BMI), perivascular fat and plasma inflammation markers of live kidney donors. We hypothesized that the BMI of donors would negatively correlate with an average increase of glomerular filtration rate (GFR) and that it would also be associated with increased perivascular and plasma inflammation markers in the first seven days after transplantation. Between January 2013 and December 2014, some 58 living kidney transplantation pairs were included in the study. Donor and recipient demographic data, preoperative BMI, blood C-reactive protein (CRP) and adiponectin levels, perivascular adipose tissue (PAT) samples and recipient blood creatinine levels were analyzed. The median CRP of donors was $0.68 \mathrm{mg} / \mathrm{l}$ ( $\max : 8.66 \mathrm{mg} / \mathrm{l}, \min : 0.33 \mathrm{mg} / \mathrm{l}$ ), the median of M1 macrophages (CD14+CD16+) in one gram of PAT was 5940 (max: 41 100, min: 248) and the median of adiponectin was 411930 pg/ml (max: 14217 000, min: 167 300) in plasma. We did not find any association between early renal graft function and the percentage of $\mathrm{M} 1$ macrophages in donor perirenal adipose tissue $(p=0.83, r=0.03, n=58)$, adiponectin $(p=0.65$, $r=0.06, n=58)$ or CRP $(p=0.16, r=0.2, n=58)$ in plasma. The obesity level of donors, expressed as BMI, did not correlate with early renal graft function in the first seven days after transplantation. The associations between ERGF and plasma and perivascular fat inflammation markers were not significant. We confirmed a negative correlation between the BMI of recipients and an average increase of GFR in the first seven days after transplantation $(p<0.02, \quad r=-0.325, N=58)$. We confirmed a negative correlation of adiponectin plasma concentration to the BMI of donors.

\section{Key words}

Living kidney donor - Obesity - Early renal graft function • Inflammation

\section{Corresponding author}

F. Thieme, Transplant Surgery Department, Institute for Clinical and Experimental Medicine, Videnska 1958, 140 21, Prague, Czech Republic. E-mail: thif@medicon.cz

\section{Introduction}

Kidney transplantation is the optimal treatment for many patients with end-stage renal disease. Due to a shortage of cadaver donor kidneys, some patients have to wait a long time for transplantation. A valid way of increasing the donor pool and reducing waiting times is through living donor kidney transplantation (De Groot et al. 2013). Excellent organ quality and ideal transplant conditions result in immediate function in the majority of living donor kidney transplantations. However, poor early graft function still occurs, although less frequently than after cadaver donor kidney transplantation. Renal transplantation is associated with a large number of risk factors that can have an influence on early renal function. One of the factors could be the increasing number of obese kidney donors (World Health 
Organisation 2007). Obesity has long been recognized as a cause of proteinuria and glomerular disease. Studies of the general population have demonstrated an increased risk of chronic kidney disease (CKD) due to obesity even after adjustment for blood pressure and diabetes (Gelber et al. 2005). According to these studies, obese patients exhibit glomerular hyperfiltration (Chagnac et al. 2003). Little is known about outcomes for overweight and obese live kidney donors and their recipients. According to a recent study, delayed graft function was adjudged to be more common among recipients of kidneys from very obese donors. The mechanisms of delayed graft function from obese kidney donors are still poorly understood and a number of primary and secondary factors could be involved. One of the factors could be ectopic perivascular fat storage and its related paracrine function, local higher oxidative stress and inflammation (Reese et al. 2009). Obese kidney transplant recipients exhibit increased delayed graft function, increased immunologic graft loss, decreased graft survival, decreased patient survival and increased post-transplant complications (Howard et al. 2001). Diet-induced fat deposition in experimental models of obesity is not limited to subcutaneous fat and classical visceral depots; it also occurs along the major blood vessels (Dwyer et al. 1995). Perivascular adipose tissue (PAT) surrounds the blood vessels in varying amounts (Yudkin et al. 2005). It seems to be able to play an active role in regulating vascular tone (Tran et al. 2008). Increased perivascular fat depots around the major vessels enhance local inflammation, promote atherosclerosis (Gustafson et al. 2015) and may affect renal and cardiovascular function (Montani et al. 2004). It is well known that adipose tissue is an important endocrine organ and that it secretes a number of different molecules which can communicate with virtually every organ in the body (Schere et al. 2006). It has a central role in the development of obesityassociated metabolic complications as well as in lowgrade systemic inflammation, and it increases the risk of atherosclerosis and cardiovascular disease (Gustafson et al. 2007). Adipose tissue contains large amounts of white line cells in addition to adipocytes. A certain proportion of monocytes/macrophages $(\mathrm{MO} / \mathrm{M} \varphi)$ is present within adipose tissue every time. The amount of these cells is increased in chronic over-nutrition when the normal physiological capacity of adipocytes is exceeded, resulting in unusually large amounts of adipocytes, which in turn leads to stress and cellular dysfunction. Atherosclerotic plaque macrophages reveal distinct phenotypes which are divided into M1 (classically activated, pro-inflammatory) and M2 (alternatively activated, anti-inflammatory) categories. The presence of proinflammatory monocytes/ macrophages co-expressing CD14 and CD16 marker $(\mathrm{CD} 14+\mathrm{CD} 16+)$ in the circulation and inflamed tissue has been documented in several inflammation conditions, such as acute inflammation, bacterial sepsis (Fingerle et al. 1993), Crohn's disease (Koch et al. 2010), and coronary heart disease (Soltis et al. 1991). Also, this subset of cells exhibits a distinct cytokine secretion pattern with a high production of proinflammatory cytokines (Belge et al. 2002) and higher potency of phagocytosis and antigen presentation compared to classic CD14+CD16- blood monocytes (Zawada et al. 2011). Recent work goes so far as to propose that the ratio of M1/M2 macrophages might play a pivotal role in the most frequent pathologies and that it is able to influence average human life expectancy, cancer and atherosclerosis occurrence (Poledne et al. 2009). Based on our data (Kralova Lesna et al. 2015) CD14+16+ tissue macrophages could be considered to be of a proinflammatory phenotype and therefore (with some simplification) regarded as M1 macrophages. Adipocytes are the main producers of subtypes of the cytokine family called adipokines (leptin, adiponectin, resistin, visfatin, etc.). Adiponectin is considered an anti-atherogenic adipokine and is produced in lower amounts in obese subjects. Levels of the hormone are inversely correlated with body fat percentages in adults. One marker of the proinflammatory state is C-reactive protein (CRP). A number of studies have revealed that inflammatory markers, including CRP and pro-inflammatory cytokines, are strong predictors of atherosclerosis. Higher concentrations of CRP analyzed by high sensitivity kit (hsCRP) together with increasing body weight are related to visceral fat volume. The positive relation of hsCRP to BMI, waist circumference and triglyceride concentration has also been documented (Poledne et al. 2009). Our aim was to investigate early renal graft function in recipients of obese live kidney donors. We hypothesized that the obesity level of donors, expressed as BMI, would negatively correlate with an average increase of GFR in the first week after transplantation and that it would also be associated with increased levels of perivascular and plasma inflammation markers. 


\section{Methods}

\section{Patients}

Donor and recipient characteristics, clinical data, and graft and patient survival statuses were retrieved from the hospital database. Laboratory data were collected retrospectively from the hospital's electronic patient file. Some 58 pairs, over a period between January 2013 and December 2014, were included in the study. Live donor inclusion criteria were: aged over 18 years, signature of informed consent. Recipient exclusion criteria were: aged under 18 years, biopsy-proven rejection of a graft. The design of the study was approved by the Ethics Committee of the Institute. All participants were fully informed about the study and signed informed consent forms.

\section{Kidney transplantation procedure}

All kidneys were procured using a hand-assisted retro-peritoneoscopic live donor nephrectomy technique. Briefly, gel-port for hands and 3 trocars were introduced at a pneumo-retroperitoneal pressure of $12 \mathrm{~mm} \mathrm{Hg}$. The renal artery, vein and ureter were divided, and the kidney was extracted via Pfannenstiel incision. Kidneys were implanted in the recipient's iliac fossa using an extraperitoneal approach with vascular anastomoses to the external iliac vessels, after which uretero-neocystostomy was performed.

All of the transplant grafts from our set exhibited immediate function after transplantation. We did not observe any poor or delayed graft function (DGF), nor slow graft function. All grafts were rejection-free. Our primary outcome was an average increase of GFR in the first seven days after transplantation.

\section{Immunosuppressive protocol}

All patients received intravenous methylprednisolone administered in the operating room and monoclonal antibody induction (Thymoglobulin) if indicated. After the induction therapy, all patients were treated with standard, triple immunosuppressive therapy consisting of a calcineurin inhibitor, mycophenolate mofetil and steroids.

\section{Treatment of samples}

Samples of adipose tissue were collected during the operation, cooled and immediately transferred to the laboratory. Each tissue sample was then dissected into small samples, exposed to collagenase and repeatedly filtered and purified. Finally, the stromal vascular fraction (SVF) was eluted from the sample. SVF was analyzed on the same day using a flow cytometry analyzer. SVF was analyzed on the same day using a flow cytometry analyzer, CyAn (Beckman Coulter). Different monoclonal antibodies and fluorochromes (CD14 Phycoerythrin-Cyanine 7, PC7, CD16 - Phycoerythrin Texas Red-X, ECD) were used to define different subsets of monocytes/macrophages. The cells of the monocyte/macrophage lineage were identified as CD14+ mononuclear cells, and based on the co-expression of CD16, CD14+16+ subset (M1 macrophages) was identified. Flow cytometry data were analyzed Kaluza software (Beckman Coulter). CRP was measured by immunoturbidimetric assay using an autoanalyzer (Cobas Mira Plus, Roche, Basel, Switzerland). Adiponectin was analyzed by Luminex ${ }^{\circledR}$ Assay kit (R\&D Systems, Minneapolis, MN).

\section{Statistical analysis}

Donor data and graft survival analyses were processed using Spearman's method. Categorical variables were given as absolute numbers of patients and percentages and were compared using Chi-square tests, $p$ values $<0.05$ were considered significant.

\section{Results}

Comparison of the population of live kidney donors with the general Czech population

A total of 58 living kidney transplantation pairs were included in the study. We compared a group of living kidney donors and recipients with a well-defined control group - the representative $1 \%$ Czech population sample ( 25 to 64 years of age, $n=3612$ ) from the PostMONICA WHO Survey in 2007/2008 (Table 1).

The average age of donors was $46 \pm 10$ years $(p=0.465)$ and the average age of recipients was $42 \pm 13$ years $(\mathrm{p}<0.001)$ compared with the $1 \%$ Czech population sample control: $47.1 \pm 11.4$ years.

The average BMI of donors was $25.8 \pm 3.6 \mathrm{~kg} / \mathrm{m}^{2}$ $(\mathrm{p}=0.006)$ and the average BMI of recipients was $25.4 \pm 4.5 \mathrm{~kg} / \mathrm{m}^{2}(\mathrm{p}=0.001)$ compared with the $1 \% \mathrm{Czech}$ population sample control: $27.8 \pm 5.5 \mathrm{~kg} / \mathrm{m}^{2}$. It was evident that living kidney donors were healthier compared to the control population. However, the prevalence of overweight and obesity is rather high in the Czech population. The BMI level of living kidney donors was on the borderline between controls and overweight. 
Table 1. Comparison of donor and recipient data with the control group - representative $1 \%$ Czech population sample.

\begin{tabular}{|c|c|c|c|c|c|c|}
\hline $\begin{array}{l}\text { Donor and recipient } \\
\text { demographic data }\end{array}$ & $\begin{array}{c}\text { Age } \\
\text { (years) }\end{array}$ & $\begin{array}{c}\text { BMI } \\
\left(\mathrm{kg} / \mathrm{m}^{2}\right)\end{array}$ & Hypertension & Dyslipidemia & $\begin{array}{l}\text { Diabetes } \\
\text { mellitus }\end{array}$ & Smoking \\
\hline $\begin{array}{l}\text { Czech population } \\
\text { sample }(n=3612)\end{array}$ & $47.1 \pm 11.4$ & $27.8 \pm 5.5$ & $43.50 \%$ & $69.80 \%$ & $8.00 \%$ & $27.00 \%$ \\
\hline Donors $(n=58)$ & $46 \pm 10$ & $25.8 \pm 3.6^{*}$ & $\begin{array}{c}18.9 \% \\
(11 / 58)^{*}\end{array}$ & $\begin{array}{l}10.3 \% \\
(6 / 58)^{*}\end{array}$ & $\begin{array}{c}0 \% \\
(0 / 58)^{*}\end{array}$ & $\begin{array}{l}34.5 \% \\
(20 / 58)^{*}\end{array}$ \\
\hline Recipients $(n=58)$ & $42 \pm 13 *$ & $25.4 \pm 4.5^{*}$ & $\begin{array}{c}81 \% \\
(47 / 58)^{*}\end{array}$ & $\begin{array}{c}38 \% \\
(22 / 58)^{*}\end{array}$ & $\begin{array}{c}18.9 \% \\
(11 / 58)^{*}\end{array}$ & $\begin{array}{l}34.5 \% \\
(20 / 58)^{*}\end{array}$ \\
\hline
\end{tabular}

$* \mathrm{p} \leq 0.05$.

Hypertension was defined as a mean systolic blood pressure (SBP) $\geq 140 \mathrm{~mm} \mathrm{Hg}$ and/or a mean diastolic blood pressure (DPB) $\geq 90 \mathrm{~mm} \mathrm{Hg}$, or according to ongoing treatment with antihypertensive drugs. The prevalence of hypertension was almost slightly below half of the control sample: $43.5 \%$. Hypertension in donors presented at $18.9 \%$; 11/58; $(\mathrm{p}<0.001)$ and, as expected, hypertension in the recipient group was more frequent than the control sample at $81 \%$; 47/58; $(\mathrm{p}<0.001)$.

Dyslipidemia was defined as total cholesterol $\geq 5 \mathrm{mmol} / \mathrm{l}, \quad$ as HDL-cholesterol $<1.1 \mathrm{mmol} / 1$, or according to ongoing use of lipid-lowering drugs. The prevalence of dyslipidemia was $69.8 \%$ in the control sample. Dyslipidemia in donors was determined at $10.3 \% ; 6 / 58 ;(\mathrm{p}<0.001)$ all of whom were treated using statins. Dyslipidemia in recipients was recorded at $38 \%$; $22 / 58$; $(<0.001) .15$ of these 22 recipients were treated using statins.

The prevalence of diabetes mellitus was $8 \%$ in the control sample. There were no donors with diabetes mellitus of $0 \% ; 0 / 58 ; \quad(p=0.046)$. The presence of diabetes is a contraindication of live kidney donation. The prevalence of diabetes in recipients was $18.9 \% ; 11 / 58$; $(p=0.006)$. One was treated by diet only, one with oral anti-diabetic drugs and 9 with insulin.

The overall proportion of smoking in the control group was $27 \%$. The prevalence of smoking was not different in both groups $-34.5 \% ; 20 / 58 ;(p=0.001)-$ but it was higher than the control sample.

Influence of live kidney donor characteristics on early graft function

The median CRP of donors was $0.68 \mathrm{mg} / \mathrm{l}$ (max: $8.66 \mathrm{mg} / 1, \min : 0.33 \mathrm{mg} / \mathrm{l}$ ), the median of M1 macrophages marker $(\mathrm{CD} 14+\mathrm{CD} 16+)$ in one gram of
PAT was 5940 (max: 41 100, min: 248) and the median of adiponectin concentration was $411930 \mathrm{pg} / \mathrm{ml}$ (max: 14217 000, min: 167 300) in plasma.

Early renal graft function, measured as an average increase of GFR in the first seven days after transplantation, did not correlate with the BMI of donors (Fig. 1).

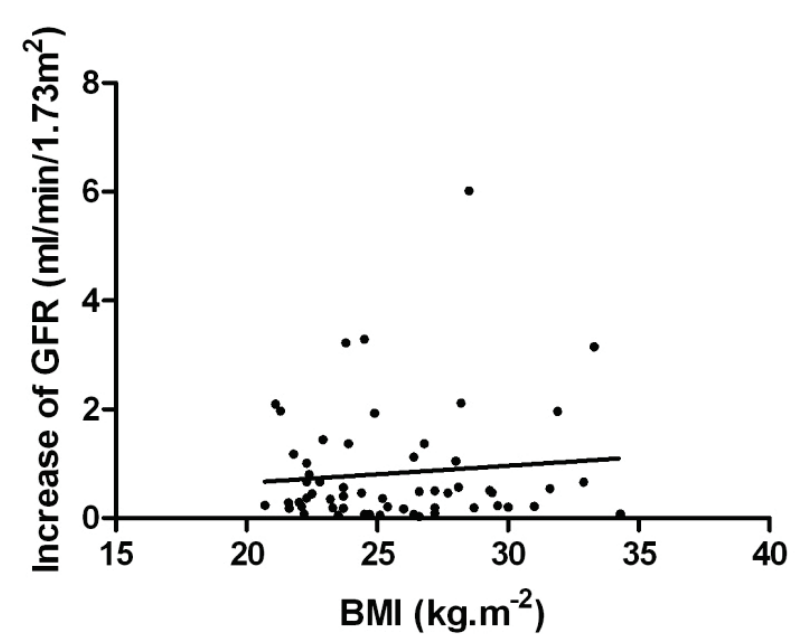

Fig. 1. Correlation of donor BMI with average GFR in recipients.

We did not find any association between early renal graft function and the percentage of M1 macrophages in donor perirenal adipose tissue $(\mathrm{p}=0.83$, $\mathrm{r}=0.03, \mathrm{n}=58)$, adiponectin $(\mathrm{p}=0.65, \mathrm{r}=0.06, \mathrm{n}=58)$ or $\mathrm{CRP}(\mathrm{p}=0.16, \mathrm{r}=0.2, \mathrm{n}=58)$ in plasma.

We confirmed a negative correlation between the BMI of recipients and an average increase of GFR in the first seven days after transplantation $(\mathrm{p}<0.02$, $\mathrm{r}=-0.325, \mathrm{~N}=58)$ (Fig. 2).

We confirmed negative correlations of adiponectin plasma concentration with donor BMI, despite our group of patients being rather small (Fig. 3). 


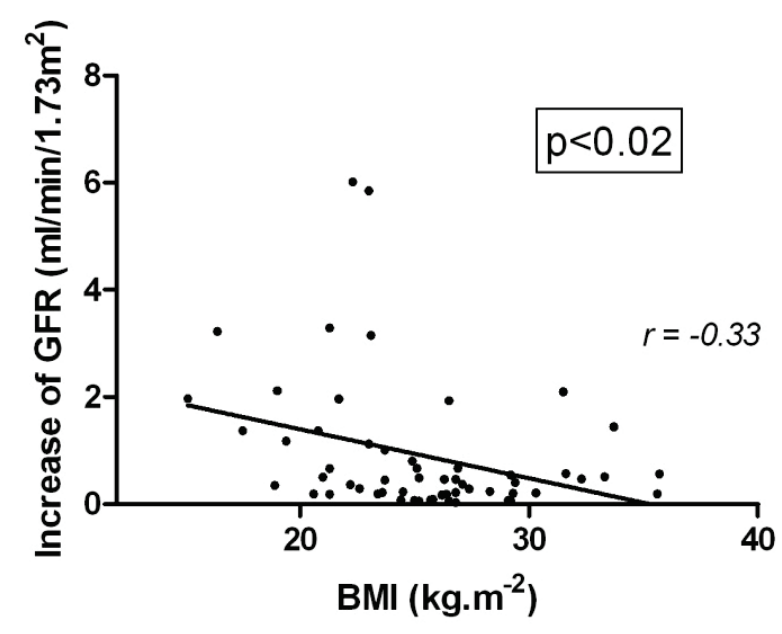

Fig. 2. Correlation of recipient BMI with average GFR in recipients.

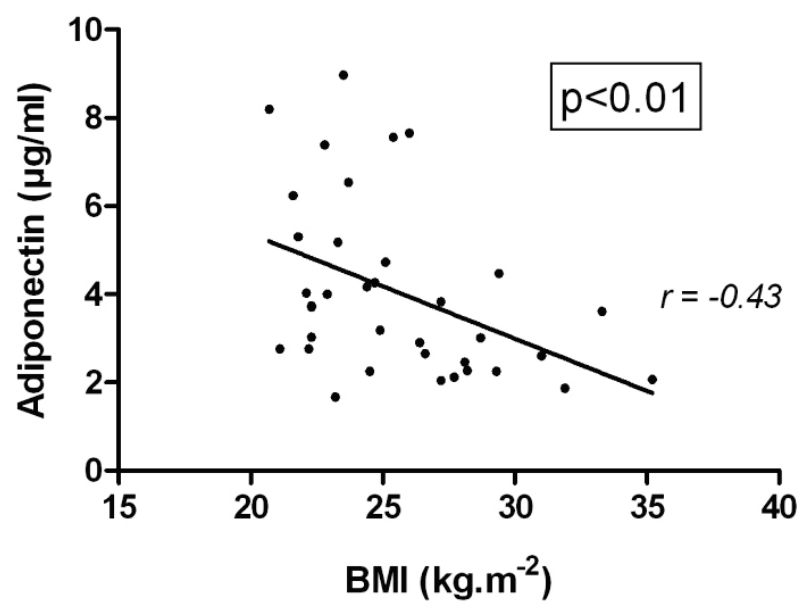

Fig. 3. Correlation of BMI with adiponectin concentrations.

\section{Discussion}

Living kidney donation is an ideal method for reducing waiting lists for cadaveric kidney transplantation (Uguz et al. 2015). The population of potential living kidney donors has become more obese, a trend observed in many countries (World Health Organisation 2007). The technique of hand-assisted retro-peritoneoscopic live donor nephrectomy is safe, both to the donor and to the kidney graft. Individuals who slightly exceed the recommended limits for hypertension, dyslipidemia and overweight are accepted (Uguz et al. 2015). Obesity (with a cut-off value of BMI $30 \mathrm{~kg} / \mathrm{m}^{2}$ ) is defined as an extended criterion for live donation in many studies. One meta-analysis, which examined outcomes for obese live donors, found that changes in GFR after nephrectomy were not greater than those among nonobese donors (Espinoza et al. 2006). It is accepted that short-term allograft survival for recipients of kidneys from donors with elevated BMI do not differ from outcomes for recipients of kidneys from normal-weight live donors (Arita et al. 1999).

Obesity does not seem to impose an undue risk for kidney transplantation, but it may predispose the recipient to DGF, particularly at the more extreme end of the spectrum (at a BMI greater than $35 \mathrm{~kg} / \mathrm{m}^{2}$ ) (Armstrong et al. 2005).

In our group of 58 living kidney donors, 8 were obese $(13.8 \%)$. However, it is worth noting that average $\mathrm{BMI}$ is in and around the borderline between normal and overweight.

As we know from other studies, the recipients of organs from obese living donors display more frequent episodes of acute rejection in comparison to recipients from non-obese living donors (Espinoza et al. 2006). All recipients in this study had an early and sharp onset of renal graft function.

We did not confirm our hypothesis that there would be a statistically significant negative correlation between the BMI of donors and an increase of GFR in the first seven days after transplantation, even within the range of normal early graft function.

We did not find any correlation between early renal graft function and the percentage of M1 macrophages in donor perirenal adipose tissue, adiponectin or CRP in plasma. This may have been due to the limitations of our study - a relatively low number of pairs enrolled and the fact that most of the donors were only mildly obese (BMI under $30 \mathrm{~kg} / \mathrm{m}^{2}$ ).

Although it is known that the obesity of recipients does not seem to be a risk factor for living kidney transplantation, we confirmed a negative correlation between the BMI of recipients and an average increase of GFR in the first seven days after transplantation. In the range of normal early graft function, differences were detected.

In the group of living kidney donors, the decreasing effect of anti-inflammatory-influencing cytokine-adiponectin was proven and might be related to GFR.

\section{Conflict of Interest}

There is no conflict of interest.

\section{Acknowledgements}

Supported by the project NT-14009-3/2013 of Ministry of Health, Czech Republic. 


\section{References}

ARITA Y, KIHARA S, OUCHI N, TAKAHASHI M, MAEDA KK, MIYAGAWA J, HOTTA K, SHIMOMURA I, NAKAMURA T, MIYAOKA K, KURIYAMA H, NISHIDA M, YAMASHITA S, OKUBO K, MATSUBARA K, MURAGUCHI M, OHMOTO Y, FUNAHASHI T, MATSUZAWA Y: Paradoxical decrease of an adipose-specific protein, adiponectin, in obesity. Biochem Biophys Res Commun 2: 79-83, 1999.

ARMSTRONG KA, CAMPBELL SB, HAWLEY CM, JOHNSON DW, ISBEL NM: Impact of obesity on renal transplant outcomes. Nephrology (Carlton) 10: 405-413, 2005.

BELGE KU, DAYYANI F, HORELT A, SIEDLAR M, FRANKENBERGER M, FRABKENBERGER B, ESPEVIK T, ZIEGLER-HEITBROCK L: The proinflammatory CD14+CD16+DR++ monocytes are a major source of TNF. J Immunol 168: 3536-3542, 2002.

CHAGNAC A, WEINSTEIN T, HERMAN M, HIRSH J, GAFTER U, ORI Y: The effects of weight loss on renal function in patients with severe obesity. J Am Soc Nephrol 14: 1480-1486, 2003.

CIFKOVA R, SKODOVA Z, BRUTHANS J, ADAMKOVA V, JOZIFOVA M, GALOVCOVA Z, WOHLFAHRT P, KRAJCOVIECHOVA A, POLEDNE R, STAVEK P, LANSKA V: Longitudinal trends in major cardiovascular risk factors in the Czech population between 1985 and 2007/2008. Czech MONICA and Czech post-MONICA. Atherosclerosis 211: 676-681, 2010.

DE GROOT IB, VEEN JI, VAN DER BOOG PJ, VAN DIJK S, STIGGELBOUT AM, MARANG-VAN DE MHEEN PJ; PARTNER-STUDYGROUP: Difference in quality of life, fatigue and societal participation between living and deceased donor kidney transplant recipients. Clin Transplant 27: E415-E423, 2013.

DWYER TM, MIZELLE HL, COCKRELL K, BUHNER P: Renal sinus lipomatosis and body composition in hypertensive, obese rabbits. Int J Obes Relat Metab Disord 19: 869-874, 1995.

ESPINOZA R, GRACIDA C, CANCINO K, IBARRA A: Effect of obese living kidney donors on the outcome and metabolic features in recipients of kidney transplantation. Transplant Proc 38: 888, 2006.

FINGERLE G, PFORTE A, PASSLICK B, BLUMENSTEIN M, STROBEL M, ZIEGLER-HEITBROCK W: The novel subset of CD14+/CD16+ blood monocytes is expanded in sepsis patiens. Blood 82: 3170- 3176, 1993.

FRONEK J, CHANG RWS, MORSY MA: Hand-assisted retroperitoneoscopic living donor nephrectomy: first UK experience. Nephrol Dial Transplant 21: 2674-2675, 2006.

GELBER RP, KURTH T, KAUSZ AT, MANSON JE, BURING JE, LEVEY AS, GAZIANO JM: Association between body mass index and CKD in apparently healthy men. Am J Kidney Dis 46: 871-880, 2005.

GUSTAFSON B, HAMMARSTEDT A, ANDERSSIN CX, SMITH U: Inflamed adipose tissue: a culprit underlying the metabolic syndrome and atherosclerosis. Arterioscler Thromb Vasc Bio 27: 2276-2283, 2007.

GUSTAFSON B, SMITH U: Regulation of white adipogenesis and its relation to ectopic fat accumulation and cardiovascular risk. Atherosclerosis 241: 27-35, 2015.

HOWARD RJ, THAI VB, PATTON PR, HEMMING AW, REED AI, VAN DER WERF WJ, FUJITA S, KARLIX JL, SCORNIK JC: Obese kidney transplant recipients have good outcomes. Transplant Proc 33: 3420-3421, 2001.

KOCH S, KUCHARZIK T, HEIDEMANN J, NUSRAT A, LUEGERING A: Investigating the role of proinflammatory CD16+ monocytes in the pathogenesis of inflammatory bowel disease. Clin Exp Immunol 161: 332- 341, 2010.

KRALOVA LESNA I, POLEDNE R, FRONEK J, KRALOVA A, SEKERKOVA A, THIEME F, PITHA J: Macrophage subsets in the adipose tissue could be modified by sex and the reproductive age of women. Atherosclerosis 241: 255-258, 2015.

MONTANI JP, CARROL JF, DWYER TM, ANTIC V, AYNG Z, DULLOO AG: Ectopic fat storage in heart, blood vessels and kidneys in the pathogenesis of cardiovascular diseases. Int $J$ Obes Relat Metab Disord 28: S58-S65, 2004.

POLEDNE R, LORENZOVA A, STAVEK P, VALENTA Z, HUBACEK J, SUCHANEK P, PITHA J: Proinflammatory status, genetics and atherosclerosis. Physiol Res 58: S111-S118, 2009.

REESE PP, FELDMAN HI, ASCH DA, THOMASSON A, SHULTS J, BLOOM RD: Short-term outcomes for obese live kidney donors and their recipients. Transplantation 88: 662-671, 2009.

SCHERE PE: Adipose tissue: from lipid storage compartment to endocrine organ. Diabetes 55: 1537-1545, 2006. 
SOLTIS EE, CASSIS LA: Influence of perivascular adipose tissue on rat aortic smooth muscle responsiveness. Clin Exp Hypertens 13: 277-296, 1991.

TRAN KV, GEALEKMAN O, FRONTINI A, ZINGARETTI MC, MORRONI M, GIORDANO A, SMORLESI A, PERUGINI J, DEMATTEIS R, SBARBATI A, CORVERA S, CINTI S: The vascular endothelium of the adipose tissue gives rise to both white and brown fat cells. Cell Metab 15: 222-229, 2012.

UGUZ A, UNSAL MG, UNALP OV, SEZER T, CELTIK A, SOZBILEN M, TOZ H, SOSCOSKUN C: Is a high body mass index still a risk factor for complications of donor nephrectomy? Transplant Proc 47: 1291-1293, 2015.

WORLD HEALTH ORGANIZATION: Obesity. 2007. http://www.who.int/topics/obesity/en/

YUDKIN JS, ERINGA E, STEHOUWER CD: "Vasocrine" signalling from perivascular fat: a mechanism linking insulin resistance to vascular disease. Lancet 365: 1817-1820, 2005.

ZAWDA AM, ROGACEV KS, ROTTER B, WINTER P, MARREL RR, FLISER D, HEINE GH: SuperSAGE evidence for CD14++CD16+ monocytes as a third monocyte subset. Blood 118: 50-61, 2011. 